\title{
O uso do Facebook na promoção da saúde: uma revisão bibliográfica sobre empoderamento e participação popular
}

\author{
The use of Facebook in the health promotion: a literature review about \\ empowerment and popular participation
}

\section{El uso del Facebook en la promoción de la salud: una revisión de la literatura sobre empoderamiento y participación popular}

\author{
Fernanda Santana Miranda, a \\ fersami25@gmail.com | http://orcid.org/0000-0001-6937-9336
}

Dais Gonçalves Rocha ${ }^{2, b}$

daisrocha@yahoo.com.br | http://orcid.org/0000-0003-1103-5930

\footnotetext{
${ }^{1}$ Fundação Oswaldo Cruz, Gerência Regional de Brasília. Brasília, DF, Brasil.

2 Universidade de Brasília, Faculdade de Ciências da Saúde, Programa de Pós-Graduação em Saúde Coletiva. Brasília, DF, Brasil.
}

\footnotetext{
a Mestrado em Saúde Coletiva pela Universidade de Brasília.

b Doutorado em Saúde Pública pela Universidade de São Paulo.
}

\section{Resumo}

Em consonância com diversas áreas da sociedade, o uso das mídias sociais tem oportunizado novas formas de comunicação e de compartilhamento de conteúdo no campo da saúde pública. O presente ensaio teórico propõe uma reflexão sobre o uso do Facebook relacionado a diretrizes e princípios presentes na Política Nacional de Humanização (PNH), na Política Nacional de Promoção da Saúde (PNPS) e na Política Nacional de Gestão Estratégica e Participativa no SUS (ParticipaSUS) do Ministério da Saúde do Brasil. São descritos, ainda, os recursos do Facebook e realizada uma revisão de literatura. Os resultados evidenciam a incipiência da temática na língua portuguesa e como essa mídia social pode contribuir para o fortalecimento da participação popular na gestão pública e para o empoderamento de indivíduos e coletividades.

Palavras-chave: Comunicação em saúde; Mídias sociais; Facebook; Empoderamento; Participação popular.

\begin{abstract}
In consonance with different spheres of the society, the use of social media has made possible new ways of communication and of content sharing in the public health field. This article suggests to think about the use of Facebook related to guidelines and principles found in the PNH - Política Nacional de Humanização (National Policy of Humanization), in the PNPS - Política Nacional de Promoção da Saúde (National Policy of Health Promotion) and in the ParticipaSUS - Política Nacional de Gestão Estratégica e Participativa no SUS (National Policy of Strategic and Participative Management in the SUS), all of them developed by the Health Ministry of Brazil. Also a Facebook's features description and a literature review have been done.
\end{abstract}


The results show that the subject in the Portuguese language is incipient and how this social media can contribute to the strengthening of popular participation in the public management and to the empowerment of individuals and communities.

Keywords: Health communication; Social media; Facebook; Empowerment; Popular participation.

\section{Resumen}

En consonancia con diversas áreas de la sociedad, el uso de los medios de comunicación sociales tiene posibilitado nuevas formas de comunicación y el intercambio de contenidos en el campo de la salud pública. El presente artículo propone una reflexión sobre el uso del Facebook relacionado a las directrices y a los principios que se encuentran en la PNH - Política Nacional de Humanização (Política Nacional de Humanización), en la PNPS - Política Nacional de Promoção da Saúde (Política Nacional de Promoción de la Salud) y en la ParticipaSUS - Política Nacional de Gestão Estratégica e Participativa no SUS (Política Nacional de Gestión Estratégica y Participativa en el SUS) desarrolladas por el Ministerio de Salud de Brasil. El presente artículo describe también los recursos del Facebook y realiza una revisión de la literatura. Los resultados muestran que la materia en lengua portuguesa es incipiente y cómo ese medio de comunicación social puede contribuir al fortalecimiento de la participación popular en la gestión pública y al empoderamiento de los individuos y de los grupos.

Palabras clave: Comunicación en la salud; Medios de comunicación sociales; Facebook; Empoderamiento; Participación popular.

Contribuição dos autores:

Concepção e desenho do estudo: Fernanda Santana Miranda e Dais Gonçalves Rocha

Aquisição, análise ou interpretação dos dados: Fernanda Miranda e Dais Gonçalves Rocha

Redação do manuscrito: Fernanda Santana Miranda

Revisão crítica do conteúdo intelectual: Dais Gonçalves Rocha

Declaração de conflito de interesses: Não houve

Fontes de financiamento: Não houve

Considerações éticas: Não há

Agradecimento/Contribuições adicionais: Não há

Histórico do artigo: Submetido: 17.jun.2017 | Aceito: 06.abr.2018 | Publicado: 29.jun.2018.

Apresentação anterior: Não houve.

Licença CC BY-NC atribuição não comercial. Com essa licença é permitido acessar, baixar (download), copiar, imprimir, compartilhar, reutilizar e distribuir os artigos, desde que para uso não comercial e com a citação da fonte, conferindo os devidos créditos de autoria e menção à Reciis. Nesses casos, nenhuma permissão é necessária por parte dos autores ou dos editores. 


\section{Introdução}

Este artigo teórico tem como objetivo propor uma reflexão sobre o uso do Facebook relacionado a políticas nacionais do Sistema Único de Saúde (SUS) e com base em estudos na área da saúde coletiva, discutindo de que forma essa mídia social, criada em 2004, pode contribuir para o processo de cogestão e para a promoção da saúde na perspectiva do empoderamento de indivíduos e de coletividades.

A relevância do tema é legitimada por dados que apontam que, no Brasil, já são cerca de 107 milhões os usuários de internet, o que corresponde a $61 \%$ da população com 10 anos ou mais de idade. Entre as atividades mais populares realizadas por $78 \%$ dos usuários de internet estão as de uso de redes sociais

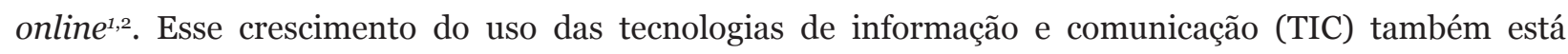
impactando o campo da saúde e provocando mudanças no acesso à informação, nas trocas de experiências entre pacientes, na relação entre médicos e pacientes e no aumento do acesso aos serviços que, por meio dessas tecnologias, podem ser ofertados de forma remota. Vale acrescentar que $23 \%$ dos estabelecimentos de saúde que utilizaram internet possuem conta ou perfil em redes sociais, a maioria deles no Facebook ${ }^{3,4}$.

Neste ensaio, destacamos os seguintes princípios: cogestão, empoderamento e participação popular, presentes na Política Nacional de Humanização (PNH), criada em 2003, na Política Nacional de Promoção da Saúde (PNPS), instituída em 2006 e revisada em 2014, e na Política Nacional de Gestão Estratégica e Participativa no SUS (ParticipaSUS), de 2009, respectivamente. A escolha dessas políticas deu-se a partir do pressuposto de que, embora o governo federal já faça uso de ferramentas online e reconheça a sua importância nos seus manuais de comunicação, a utilização das mídias sociais como um dispositivo para estimular a cogestão, o empoderamento e a participação popular - princípios presentes nas referidas políticas nacionais de saúde -, ainda não é uma realidade. Assim, este estudo também buscou refletir sobre o uso das TIC pelo governo federal quanto ao potencial que as mídias sociais têm de promover a participação popular e práticas horizontais de gestão, bem como de motivar, auxiliar e aprimorar o desenvolvimento e a adoção de novas iniciativas de governo eletrônico. O conceito de e-gov está relacionado não só com a evolução das TIC, como também com a necessidade de modernização do Estado e com a sua forma de se relacionar com a sociedade; ele deve estar alinhado aos objetivos da comunicação de governo, como: fortalecimento da democracia, prestação de contas à sociedade, transparência e comunicação aos cidadãos ${ }^{5}$.

O levantamento bibliográfico sobre o uso do Facebook na saúde foi realizado a partir de livros e artigos científicos publicados, preferencialmente, nos últimos dez anos, considerando que foi em 2006 que o Facebook passou a ser um dispositivo aberto e começou a aceitar o cadastro de qualquer pessoa, acima de 13 anos, com um e-mail válido. Antes, para poder ter acesso ao site de rede social, era preciso estar matriculado em uma universidade, portanto, não era uma ferramenta acessível a todos ${ }^{6,7}$. A base de dados consultada foi a PubMed, que indexa literatura especializada relativa às ciências da saúde. As palavraschave utilizadas na busca foram: "facebook and health promotion" "facebook and empowerment". Foram encontrados 164 artigos sobre o tema e, destes, foi possível ter acesso a 95 publicações, das quais 34 foram analisadas por tratarem especificamente do Facebook. Também foi realizada uma análise documental da Política Nacional de Humanização (PNH), da Política Nacional de Promoção da Saúde (PNPS) e da Política Nacional de Gestão Estratégica e Participativa no SUS (ParticipaSUS) ${ }^{8-10}$.

\section{Saúde, empoderamento e políticas nacionais}

Quando foi promulgada a Constituição Federal de 1988, houve uma importante redefinição das prioridades da política do Brasil na área da saúde pública. A saúde passou a ser um direito de todos e dever do Estado (Art. 196) e o Sistema Único de Saúde (SUS) se formalizou. Segundo Paim", "pela primeira vez na história do Brasil, foi promulgada uma Constituição que reconhece a saúde como direito social”. O SUS é constituído 
pelo conjunto das ações e de serviços para promoção, proteção e recuperação da saúde sob a gestão pública e é regulado pela Lei Orgânica da Saúde, aprovada em 19 de setembro de 1990 (Lei 8.080/90)12. Mas foi somente em 28 de dezembro de 1990, com a publicação da Lei Federal 8.142 ${ }^{13}$, que a participação da comunidade na gestão do SUS ganhou força. A partir dessa data, a sociedade civil e organizada passou a ter dois espaços permanentes de manifestação, que são as conferências de saúde e os conselhos de saúde. O usuário passou a ter um espaço institucionalizado para atuar no planejamento, na formulação de estratégias, na execução e fiscalização das políticas de saúde, bem como na gestão financeira e administrativa do SUS ${ }^{13}$.

Desde a sua criação em 1988, O SUS continua em construção e vem passando por constantes transformações. Ao longo desses anos, o Ministério da Saúde (MS) tem criado diversas políticas públicas de saúde. Entre elas, destaca-se a Política Nacional de Humanização (PNH) ${ }^{8}$, criada em 2003, com o objetivo de colocar em prática os princípios do SUS no cotidiano dos serviços de saúde, produzindo mudanças nos modos de gerir e cuidar. A PNH atua de forma transversal às demais políticas de saúde, a fim de impactá-las e interferir na qualificação da atenção e gestão do SUS'.

O HumanizaSUS, como também é conhecida a Política Nacional de Humanização, se pauta em três princípios: inseparabilidade entre a atenção e a gestão dos processos de produção de saúde, transversalidade, e autonomia e protagonismo dos sujeitos. Entre as diretrizes que norteiam a PNH estão acolhimento, gestão participativa e cogestão, ambiência, clínica ampliada e compartilhada, valorização do trabalhador e defesa dos direitos dos usuários. Desta forma, a PNH busca estimular a cogestão e a comunicação entre gestores, trabalhadores e usuários para construir processos coletivos de enfrentamento de relações de poder8. Conforme propôs Campos ${ }^{14}$, ainda no final da década de 1990 "assim, o Método de Gestão colegiada baseia-se, não na ideia de autogestão, mas no conceito de cogestão. Todos participam do governo, mas ninguém decide sozinho ou isolado ou em lugar dos outros. As funções de dirigente ou de liderança não estariam eliminadas neste modo de governar, somente não assumiriam um caráter exclusivo e unipessoal. De um dirigente-titular, suposto sabido e todo-poderoso, saltar-se-ia para um Colegiado composto por diretores e coordenadores de cada uma das Unidades de Produção"14.

A Política Nacional de Promoção da Saúde (PNPS)9 é um outro exemplo de política pública criada pelo Ministério da Saúde que também dialoga com a PNH. Instituída em 2006 e revisada em 2014, a PNPS ${ }^{9}$ define promoção da saúde como "um conjunto de estratégias e formas de produzir saúde, no âmbito individual e coletivo". Além do seu objetivo de promover a qualidade de vida, ampliar a potencialidade da saúde individual e coletiva e reduzir a vulnerabilidade e os riscos à saúde relacionados aos seus determinantes sociais, a PNPS visa promover o empoderamento e a capacidade para a tomada de decisão, bem como a autonomia de sujeitos e de coletividades ${ }^{11}$. Neste sentido, Czeresnia ${ }^{15}$ reforça que o conceito de promoção deve ser relacionado com o de fortalecimento da capacidade individual e coletiva de lidar com a diversidade dos condicionantes da saúde. Ressalta que promoção vai além de questões técnicas e normativas e destaca a importância do fortalecimento da saúde, por meio da construção de capacidade de escolha e do uso do conhecimento.

Um dos princípios da PNPS, o empoderamento é definido pela referida política como "um processo de intervenção que estimula os sujeitos e coletivos a adquirirem o controle das decisões e das escolhas de modos de vida adequados às suas condições socioeconômicas e culturais" " O termo empoderamento vem da palavra inglesa empowerment, expressão que surgiu nos anos 1970 com os movimentos negros e feministas que lutavam pelos direitos civis nos Estados Unidos ${ }^{16}$. Empoderamento também pode ser definido sob a perspectiva de Paulo Freire, que embora não tenha trabalhado especificamente sobre tal conceito, inspirou autores que estudam o tema e também profissionais de saúde empenhados na mudança social ${ }^{17}$. Trata-se de uma perspectiva emancipatória que compreende o empoderamento como um espaço de transformação da realidade, de emancipação humana e de libertação ${ }^{18}$. Neste contexto, entende-se que o empoderamento não se dá a partir da transferência de poder e de informações em nome de um bem comum, mas sim a partir do diálogo de conflito de interesses entre os sujeitos, grupos e classes sociais, de um caráter relacional e de sua interdependência com a noção de participação, imprescindível para a transformação social ${ }^{19}$. 
Wallerstein ${ }^{20}$ evidencia os avanços conceituais, já conquistados desde os anos 1990, sobre as duas dimensões do conceito de empoderamento: empoderamento psicológico individual e empoderamento social. Essa abordagem propõe superar as estratégias de culpabilização dos indivíduos e a construção hierárquica de conhecimento de modo a avançar para a cogestão do conhecimento e, por consequência, também da saúde e da produção do cuidado.

Elaborada pela Secretaria de Gestão Estratégica e Participativa (SGEP), do MS, em 2009, a Política Nacional de Gestão Estratégica e Participativa no SUS (ParticipaSUS) ${ }^{10}$ também é uma política transversal que tem, inclusive, como uma de suas atribuições apoiar a PNH. Entre os seus princípios está a reafirmação dos pressupostos da Reforma Sanitária, como a participação social e a valorização dos diferentes mecanismos de controle social nos processos de gestão do SUS. O documento também traz, como uma de suas diretrizes, a ampliação dos espaços de ausculta da sociedade em relação ao SUS, articulando-os com a gestão do sistema e a formulação de políticas públicas de saúde ${ }^{10}$.

Dessa forma, a ParticipaSUS reforça a necessidade de ampliação de espaços públicos e coletivos para a prática do diálogo com profissionais de saúde, gestores e a comunidade, visando à construção de um conhecimento compartilhado sobre a saúde. Essa demanda é reiterada em diversos momentos da referida política, que destaca a ampliação dos atuais canais de interlocução entre usuários e sistema de saúde como um dos principais desafios para a consolidação e o fortalecimento do controle social no SUS, apontados nas conferências de saúde ${ }^{10}$.

Outro componente importante da ParticipaSUS é o fortalecimento da ouvidoria-geral do SUS, criada em 2003, com o objetivo de propor, coordenar e implementar a Política Nacional de Ouvidoria em Saúde no âmbito do SUS. A política em pauta reconhece que esse é um mecanismo fundamental para fortalecer o controle social e a gestão participativa, na medida em que é por meio das ouvidorias que o cidadão pode se manifestar e fazer reclamações, denúncias, sugestões, elogios e solicitação de informações. Além disso, os gestores podem se utilizar desse canal de comunicação para a produção de informações que subsidiam as tomadas de decisão ${ }^{10}$.

Nesse sentido, é importante que o gestor federal fortaleça os canais de comunicação já existentes, mas que também compreenda e potencialize o uso das TIC e das ferramentas virtuais dentro da gestão pública, em especial as redes sociais.

\section{Sociedade em rede}

A internet e as formas pelas quais os usuários a acessam têm passado por várias transformações. A web 2.o, termo utilizado para designar a segunda geração de internet, trouxe uma série de inovações no que concerne às TIC. Entre as principais novidades tecnológicas, estão a interatividade, a troca de informações e a colaboração dos internautas, que compartilham textos, fotos e vídeos por meio de computadores e dispositivos móveis33.

Para Castells ${ }^{21}$, estamos passando por um processo de transformação estrutural associado a um novo paradigma tecnológico baseado nas TIC, chamado pelo autor de sociedade em rede. A noção de redes sociais tem sua origem no campo das ciências sociais, que aborda alguns tipos de relações entre as pessoas. Compreender as redes sociais no ambiente da internet, também conhecidas como redes sociais online ou digitais, requer considerar características específicas do espaço virtual. De acordo com Recuero ${ }^{22}$ as redes sociais na internet são constituídas basicamente pelo conjunto de dois elementos, que são os atores sociais, ou seja, as pessoas envolvidas na rede e as suas conexões. Assim, a autora ressalta que é importante diferenciar as redes sociais dos sites que as suportam. O Facebook, por exemplo, é um site de redes sociais, ou mídia social, que abriga diversas redes sociais e que possui os mais variados atores que interagem entre si. Outros elementos, citados por Machado $^{23}$, que passam a desempenhar papéis fundamentais para a formação das redes são a identidade e a horizontalidade que, por sua vez, favorecem a cooperação e a solidariedade

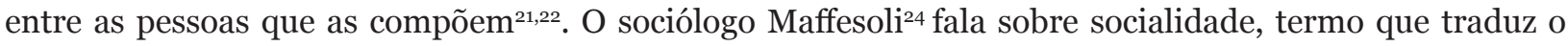


sentimento que organiza a vida em comunidade, em que o homem não é considerado mais isoladamente e se constitui pela prática do "estar-junto à toa"24.

Dessa forma, Machado ${ }^{23}$ argumenta que a internet contribui para o empoderamento das pessoas, na medida em que é um espaço público com poucas mediações. O autor destaca, ainda, que "novas formas de alianças e sinergias surgem, alicerçadas no idealismo e voluntarismo, que potencializam as formas de mobilização, participação, interação, acesso à informação e provisão de recursos"23.

Considerando que o crescimento do uso das mídias sociais tem oportunizado novas formas de comunicação e de compartilhamento de conteúdo em diversas áreas da sociedade, optou-se neste estudo por analisar o Facebook por ser a mídia social mais utilizada em todo o mundo ${ }^{25}$.

\section{Facebook}

Lançado em 4 de fevereiro de 2004, o Facebook é um site de redes sociais, que tem como missão dar às pessoas o poder de compartilhar informações ${ }^{6}$. Atualmente, é a maior mídia social do mundo com 1,59 bilhão de contas ativas ${ }^{25}$. O Brasil é o terceiro país em número de usuários, com 99 milhões de contas ativas, atrás apenas dos Estados Unidos e da Índia ${ }^{25}$. O Facebook é a mídia social mais utilizada pelos brasileiros (83\%), em segundo lugar vem o Whatsapp (58\%) e, em seguida, o Youtube $(17 \%)^{2,25}$.

Criado pelos então estudantes da Universidade de Harvard, Mark Zuckerberg, Dustin Moskovitz, Eduardo Saverin e Chris Hughes, o Facebook tinha como objetivo inicial ser uma plataforma de relacionamento fechada apenas para os universitários. Mas a rede foi crescendo rapidamente e, em 2005, o Facebook já contava com mais de duas mil universidades e 25.00o colegiais dos Estados Unidos, Canadá, México, Reino Unido, Austrália, Nova Zelândia e Irlanda. Em 26 de setembro de 2006, o Facebook abriu para todos com mais de 13 anos de idade que possuíssem um e-mail válido ${ }^{6,7}$.

O Facebook é uma plataforma digital bastante dinâmica e está sempre lançando novidades, como novas ferramentas de interação e novo layout. Permite que vários jogos e aplicativos sejam incorporados a ele para que os usuários interajam entre si ou com a própria ferramenta ${ }^{7}$. Para compreender o Facebook, é importante conhecer sua arquitetura da informação, mas para este estudo serão descritos apenas seus principais espaços e recursos:

a) Perfil: para criar uma conta do Facebook, o usuário, que deve ter idade acima de 13 anos, precisa acessar o site www.facebook.com e preencher um cadastro com nome, endereço de $e$-mail, senha, data de nascimento e gênero e, assim, criar o seu perfil. É por meio dessa identidade virtual que o usuário poderá enviar ou receber convite de amizade para ampliar a sua rede, participar de grupos, postar vídeos, fotos, textos e interagir com outras pessoas e páginas ${ }^{6}$.

b) Página: a página ou fanpage, como também é conhecida, é destinada às marcas, empresas, organizações e figuras públicas, tendo como objetivo a interação com um público específico. Diferente do perfil, a página é aberta a todos, não necessitando o usuário ser aceito ou não pelo administrador da página. Basta o usuário clicar no botão curtir, que ele poderá acompanhar as atualizações da página e começar a interagir com ela ${ }^{6}$.

c) Grupo: criados em 2010, os grupos são espaços para as pessoas conversarem sobre interesses em comum. São comunidades virtuais onde as pessoas falam sobre os mais variados temas ou sentimentos como um time de futebol, uma doença, um autor ou uma religião. Este tem sido um espaço cada vez mais utilizado para reunir pacientes com doenças graves ou crônicas, que formam rede de apoio para troca de dicas, conselhos e orientações e para pesquisar grupos específicos conforme aponta revisão de literatura ${ }^{26,27}$. Existem três opções de privacidade nos grupos: aberto (qualquer usuário pode ver o grupo, quem está nele e o que membros publicam); fechado (qualquer usuário pode ver o grupo e quem está nele. Somente membros 
podem ver as publicações) e secreto (somente membros podem ver o grupo, quem está nele e o que os membros publicam $)^{6}$.

d) Mensagem e bate-papo: por meio da mensagem o usuário pode interagir instantaneamente com outra pessoa. Este é um ambiente privado e o bate-papo pode ocorrer com mais de duas pessoas, mas caso um usuário não queira participar da interação, ele pode simplesmente sair da conversa ${ }^{6}$.

e) Feed de notícias: é uma lista constantemente atualizada com as publicações de amigos e páginas que fazem parte da rede do usuário. O algoritmo do Facebook usa critérios para determinar o que aparece no feed de notícias da pessoa. Estas atualizações são influenciadas pelas suas conexões e atividades e ela verá mais postagens das pessoas e páginas com quem mais interage. No entanto, caso o usuário não esteja vendo histórias que gostaria ou está vendo aquelas que não gostaria, ele pode ajustar em suas configurações ${ }^{6}$.

f) Timeline: é o espaço onde o usuário coloca suas postagens, podendo ser uma foto, um texto, um vídeo, um check in em algum lugar, o compartilhamento de alguma publicação de um amigo ou de uma página, um sentimento ou alguma atividade. Funciona como a linha do tempo do usuário 6 .

g) Curtir/Reagir: quando um usuário clica em curtir embaixo de alguma publicação indica que esta pessoa gostou da postagem. Lançado em 2010, o botão curtir passou ser o grande ícone do Facebook. Este botão também deve ser utilizado quando um usuário deseja seguir uma página e acompanhar as suas atualizações. Em 2016, o Facebook incluiu os botões de reação "amei", "haha", "uau", "triste" e "grr", o que ampliou a possibilidade de o usuário demonstrar seu sentimento com apenas um clique. Lembrando que ele só pode ter uma reação por publicação ${ }^{6}$.

h) Eventos: este recurso permite que o usuário organize encontros no mundo virtual e participe dele no mundo real. Ao receber um convite para participar de um evento, ela pode aceitar, demonstrar interesse ou recusar. Pacientes com problemas clínicos semelhantes utilizam esse espaço para promover reuniões, palestras e encontros ao vivo ${ }^{28}$. Ao aceitar, o usuário receberá as notificações do evento que pode ser de qualquer natureza, desde um congresso a um piquenique no parque ${ }^{6}$.

Além dessas funcionalidades e possibilidades, o Facebook tem se destacado como uma importante fonte de informação e de mobilização social, e como um espaço de troca de experiências entre usuários. Assim, a incorporação do uso das mídias sociais, em especial do Facebook, no campo da saúde também pode se revelar como uma poderosa ferramenta para o fortalecimento da participação popular e da promoção da saúde, conforme assinala Santos ${ }^{29}$ "as comunidades virtuais e os espaços interativos da Internet podem ser lugares privilegiados para a educação não-formal e para a promoção da saúde. Isso porque estabelecem um sistema capaz de incorporar diferentes espaços-tempo, práticas e culturas; enfim, um conjunto de elementos diversos que se ‘comunicam' não pelo envio de mensagens, mas pela sincronização promovida por dispositivos construídos a partir de particularidades locais, que se incorporam a uma rede global. Essas comunidades podem construir e consolidar culturas diferentes, permitindo a sua sobrevivência em um mesmo sistema. Sobrevivência que não se dá pela exclusão ou pelo isolamento, mas pela sua redefinição permanente no processo de sincronização mais geral com outras culturas e com o conjunto do sistema"29.

Nesse sentido, as diversas inovações nas áreas das TIC e nas mídias sociais estão impactando o campo da saúde e provocando mudanças nos sistemas de informação em saúde, no acesso à informação, nas trocas de experiências entre pacientes, e na relação entre médicos e pacientes. As mídias sociais também possibilitam personalizar as mensagens de acordo com o perfil de cada usuário ou grupo, o que pode contribuir para uma melhor compreensão de temas específicos sobre saúde ${ }^{3,30}$.

Para Dziekaniak ${ }^{11}$, nas mídias sociais são encontradas informações que podem identificar demandas, necessidades, críticas e sugestões dos cidadãos sobre essas plataformas. A pesquisadora salienta que o conhecimento empírico adquirido nas mídias sociais e que é produzido pelos cidadãos deveria ser transformado em conhecimento documentado para que posteriormente fosse utilizado pelo gestor federal ${ }^{31}$. Essa ideia 
dialoga com um dos eixos operacionais da PNPS sobre comunicação social e mídia, que contempla o uso de expressões comunicacionais, formais e populares para favorecer a escuta e a vocalização dos envolvidos ${ }^{9}$.

Em uma revisão geral de uma revisão sistemática realizada por Welch, Petkovic, Pardo, Rader e Tugwell ${ }^{22}$ sobre o uso das mídias sociais na promoção da equidade em saúde, na qual foram analisados onze artigos, concluiu-se que o uso dessas ferramentas foi efetivo para a promoção da equidade em saúde de determinadas populações consideradas em desvantagem (jovens, adultos mais velhos, pessoas com baixo nível socioeconômico e do meio rural). O estudo também mostrou que o uso das mídias sociais na promoção da saúde pode remover as barreiras físicas e geográficas.

Em outro estudo, Gabarron e Wynn ${ }^{33}$ fazem uma revisão de literatura a fim de verificar o uso das mídias sociais na promoção da saúde sexual. Os autores encontraram 51 publicações, das quais um quarto apresentou resultados promissores e evidenciou efeitos positivos do uso das mídias sociais na promoção da saúde sexual. Gabarron e Wynn ${ }^{33}$ também apontam para a necessidade de mais estudos que abordem explicitamente seu quadro teórico para que aumente a base de evidências do campo.

Em uma revisão de literatura sobre o uso do Facebook no cuidado oncológico, Venerone, Ferrari, Massimino e Clerici ${ }^{28}$ analisaram 57 artigos, divididos em três categorias: uso do Facebook para o apoio psicossocial, para o relacionamento médico-paciente e para comunicação institucional. Embora os autores tenham identificado aspectos críticos no uso dessa ferramenta, como as relativas à privacidade do paciente, concluiu-se que nesse espaço os médicos podem promover ações e debates sobre saúde e que, para o paciente jovem oncológico, o Facebook pode ajudar no tratamento e no combate ao isolamento, permitindo-lhe manter-se conectado com os amigos.

Por outro lado, também é fundamental considerar questões como privacidade e ética nas redes sociais. Estes temas foram pesquisados por Martorell, Nascimento e Garrafa ${ }^{34}$, que estudaram a exposição de imagens de pacientes promovida por médicos e cirurgiões dentistas no Facebook. Ao analisarem 39 imagens publicadas por 17 profissionais, os autores identificaram quebra de confidencialidade e/ou privacidade. $\mathrm{O}$ artigo ressalta que essas exposições prejudicam o paciente e infligem os direitos humanos universais. Recomenda que cursos da área de saúde incorporem discussões sobre a publicação de imagens de pacientes na internet e que este tema seja trabalhado pelas disciplinas de bioética.

$\mathrm{Na}$ Austrália, os pesquisadores Kite, Foley, Grunseit e Freeman ${ }^{35}$ realizaram uma pesquisa que procurou identificar as características das mensagens do Facebook que promovem um maior envolvimento dos usuários australianos com as páginas das instituições de saúde pública daquele país. O estudo reuniu 20 páginas que evidenciaram que postagens com elementos de patrocínios e parcerias e uso de autoridades geraram menos curtidas, comentários e compartilhamentos por parte dos usuários em comparação com as publicações com nenhum marketing. Já as postagens que contaram com a participação de alguma celebridade ou com o apelo emocional positivo ou informações factuais geraram mais interações entre os usuários.

No Brasil, uma pesquisa realizada por Cadaxa, Souza e Mendonça ${ }^{30}$ buscou identificar conteúdos promotores de saúde em postagens nas páginas de Facebook do Ministério da Saúde, do Brasil e do Peru, durante a campanha do Dia Mundial de Luta contra a Aids. O estudo apontou que a maior parte das publicações nos dois países tinha enfoque individual para mudança de comportamento relacionado à prevenção e detecção de casos de HIV: 34 (50,0\%) para o Brasil e 17 (45,9\%) para o Peru. Para as autoras, as postagens encontradas no Facebook ainda são bastante centradas no indivíduo e nas instituições, necessitando uma maior articulação com marcadores sociais como identidade sexual, posição socioeconômica, escolaridade e questões de gênero.

Atualmente, o Ministério da Saúde possui uma página oficial no Facebook, por meio da qual são divulgadas campanhas, agendas, programas e ações propostas por ele e uma outra intitulada diálogo nas redes, que busca a qualificação da saúde por meio do diálogo com a população. No entanto, em ambas as páginas é recorrente o fato de perguntas de usuários ficarem sem respostas. Embora o MS possua algumas outras páginas no Facebook com temas específicos, como dengue e aids, e tenha sido um dos órgãos 
pioneiros no uso das mídias sociais, tendo iniciado suas atividades no meio digital em 2007, são escassos seus procedimentos que estimulem o debate e a participação popular nas suas ações ${ }^{3,36}$.

Não basta o cidadão saber que tem o direito de atuar no planejamento e ou na fiscalização do SUS, é imprescindível que se crie canais e viabilize o debate e a articulação entre todos os atores: cidadão, gestor e profissional de saúde, como preconiza o ParticipaSUS. Desta forma, o Facebook apresenta-se como mais um espaço, em que o governo eletrônico pode atuar mais efetivamente, pois o uso das tecnologias pelos cidadãos oportuniza, de forma rápida e personalizada, a comunicação entre a sociedade e o Estado e entre os próprios cidadãos.

O conceito de governo eletrônico (e-gov) está diretamente relacionado com a evolução das TIC e a necessidade de modernização na forma de se relacionar com a sociedade. De acordo com o seu portal ${ }^{5}$, as ações do programa do e-gov buscam democratizar o acesso à informação e ampliar o debate e a participação popular na construção das políticas públicas por meio das TIC, tendo como uma das suas principais diretrizes a participação cidadã.

Diante desse cenário, a cogestão citada no HumanizaSUS ${ }^{8}$ e idealizada por $\operatorname{Campos}^{14}$, que afirma que todos devem participar do governo e destaca a gestão colegiada nos diferentes espaços de gestão da saúde, encontra reforço no âmbito dos sites de redes sociais, a partir do seu reconhecimento pela governança pública como este sendo um espaço farto de conteúdo e insumos, dos quais o Estado pode se valer, fortalecendo, assim, a participação dos cidadãos na coprodução de suas ações e políticas públicas ${ }^{31}$.

Da mesma forma, quando um gestor federal acompanha e considera as discussões protagonizadas pelos cidadãos numa mídia social como o Facebook e utiliza-se dessas informações para a melhoria dos seus serviços, ele contribui não só para a participação popular na gestão pública, mas também para o empoderamento desses indivíduos.

Uma iniciativa bem-sucedida realizada pelo HumanizaSUS no espaço virtual é a criação da Rede HumanizaSUS (RHS), que funciona como um ambiente colaborativo em rede, no qual os cidadãos se comunicam e expressam suas impressões, vivências e experiências sobre o SUS. No ar desde 2008, a Rede HumanizaSUS possui estrutura de blog, mas desde que criou um perfili e uma fanpage no Facebook ampliou as ações realizadas pela plataforma da RHS, atraindo novos seguidores ${ }^{37}$.

\section{Considerações finais}

As três políticas - PNPS, HumanizaSUS e a ParticipaSUS - mencionadas neste artigo apontam para a necessidade de ampliação da participação popular no governo federal e para práticas horizontais de gestão. Neste sentido, comunicação, por meio das mídias sociais, configura-se como uma peça importante nesse processo. Quando se fala de escuta na PNH, espera-se que ela seja realizada de forma qualificada e acolhedora. Assim, quando o governo escuta o usuário do SUS, a partir de uma página de Facebook, que fala de algum tema específico de saúde, por exemplo, e tenta junto com ele atuar sobre uma questão de saúde, a escuta passa a ser mais personalizada e o protagonismo do usuário no processo de saúde, adoecimento e tratamento é levado em conta. O gestor federal não aparece aqui como o único detentor do saber e da informação pronta e acabada que será transmitida ao usuário. O conhecimento é construído coletivamente: cidadão, trabalhador e gestor.

Mais do que trazer respostas, este artigo pretende suscitar reflexões e despertar o interesse para as potencialidades dos usos das mídias sociais: uma vez que o governo federal já reconhece essas mídias como um canal que possui um grande potencial de motivar, auxiliar e aprimorar o desenvolvimento e a adoção de novas iniciativas de governo eletrônico, por que os canais existentes ainda não são utilizados pelo Ministério

i @RedeHumanizaSUS 
da Saúde como um instrumento que fomenta o debate e a participação popular nas suas ações? Os gestores federais conhecem as potencialidades do Facebook? Enxergam o Facebook como uma mídia social capaz de promover a saúde e o empoderamento de sujeitos e coletividades?

Outro ponto a ser considerado é o da produção de conhecimento que essa área tem gerado nos últimos cinco anos, evidenciado, principalmente, na revisão de literatura na língua inglesa. Com relação à formação dos profissionais da saúde, o uso das mídias sociais nas práticas de atenção e gestão também se mostra um tema transversal necessário na construção de competências de comunicação e promoção da saúde, incluindo os aspectos éticos de garantia da privacidade e confidencialidade ${ }^{34}$.

É importante ressaltar que nada substitui o encontro presencial e a relação face a face. No entanto, a proximidade física não garante necessariamente que uma relação entre duas ou mais pessoas será construída, pois, conforme Martino ${ }^{38}$ argumenta, o mais importante é a proximidade funcional, ou seja, a percepção de proximidade com a outra pessoa. E essa sensação pode ser construída tanto no ambiente físico quanto no virtual.

\section{Referências}

1. Comitê Gestor da Internet no Brasil. Pesquisa sobre o uso das tecnologias da informação e da comunicação no Brasil: TIC Domićlíos 2016. São Paulo; 2017.

2. Presidência da República (BR). Secretaria de Comunicação. Pesquisa brasileira de mídia 2015: hábitos de consumo de mídia pela população brasileira. Brasília; 2014.

3. Cadaxa AG. Conteúdos Promotores de saúde em campanha de AIDS: o que diz o Facebook dos Ministérios da Saúde do Brasil e do Peru? [dissertação]. Brasília: Universidade de Brasília; 2014.

4. Comitê Gestor da Internet no Brasil. Pesquisa sobre o uso das tecnologias da informação e da comunicação nos estabelecimentos de saúde brasileiros: TIC Saúde 2014. São Paulo; 2015.

5. Ministério do Planejamento, Desenvolvimento e Gestão (BR). Governo Digital [Internet]. Brasília; 2015. Histórico do Programa de Governo Eletrônico Brasileiro; 2015 mar. 31 [citado em 2016 out. 23]. Disponível em: http://www.governoeletronico.gov.br/sobre-o-programa/historico

6. Facebook. Central de ajuda [Internet]. 2018 [citado em 2016 mar. 23]. Disponível em: https://www. facebook.com/help/?helpref=facebar dropdown help

7. Silva TP. Ambientes de interação em rede para a saúde: a prática de educação e pesquisa do Núcleo de Experimentação de Tecnologias Interativas da Fiocruz no Facebook. [dissertação]. Rio de Janeiro: Fiocruz; 2013.

8. Ministério da Saúde (BR). Secretaria de Atenção à Saúde. Política Nacional de Humanização. Brasília; 2003.

9. Ministério da Saúde (BR). Secretaria de Atenção à Saúde. Política Nacional de Promoção da Saúde. Brasília; 2006.

10. Ministério da Saúde (BR). Secretaria de Gestão Estratégica e Participativa. Política Nacional de Gestão Estratégica e Participativa no SUS: ParticipaSUS. Brasília; 2009.

11. Paim JS. O que é o SUS. Rio de Janeiro: Fiocruz; 2009.

12. Presidência da República (BR). Casa Civil, Subchefia de Assuntos Jurídicos. Lei n. 8.080, de 19 de setembro de 1990. Dispõe sobre as condições para a promoção, proteção e recuperação da saúde, a organização e o funcionamento dos serviços correspondentes e dá outras providências. DOU [Internet]. 1990 set. 20 [citado em 2018 maio 04]. Disponível em: http://www.planalto.gov.br/ccivil 03/leis//8080.htm

13. Presidência da República (BR). Casa Civil, Subchefia de Assuntos Jurídicos. Lei n. 8.142, de 28 de dezembro de 1990. Dispõe sobre a participação da comunidade na gestão do Sistema Unico de Saúde (SUS) e sobre as transferências intergovernamentais de recursos financeiros na área da saúde e dá outras providências. DOU [Internet]. 1990 dez. 31 [citado em 2018 maio 04]. Disponível em: http:// conselho.saude.gov.br/legislacao/lei8142 281290.htm 
14. Campos GWS. O anti-Taylor: sobre a invenção de um método para cogovernar instituições de saúde produzindo liberdade e compromisso. Cad. Saúde Pública [Internet]. 1998 [citado em 2016 abr. 26];14(4):863-70. doi: http://dx.doi.org/10.1590/S0102-311X1998000400029

15. Czeresnia D. Conceito de saúde e a diferença entre prevenção e promoção. In: Czeresnia D, Freitas CM, organizadores. Promoção da saúde: conceitos, reflexões, tendências. 2 ed. Rio de Janeiro: Editora Fiocruz; 2012.

16. Antunes M. O caminho do empoderamento: articulando as noções de desenvolvimento, pobreza e empoderamento. In: Romano $\mathrm{JO}$, Antunes $\mathrm{M}$. Empoderamento e direitos no combate à pobreza. Rio de Janeiro: ActionAid Brasil; 2002. p. 39-53.

17. Carvalho S, Gastaldo D. Promoção à saúde e empoderamento: uma reflexão a partir das perspectivas crítico-social pós-estruturalista. Ciênc. Saúde Coletiva [Internet]. 2008 [citado em em 2016 fev. 25];13(2):2029-40. doi: http://dx.doi.org/10.1590/S1413-81232008000900007

18. Barreto R, Paula A. "Rio da Vida Coletivo": empoderamento, emancipação e práxis. Rev. Adm. Pública [Internet]. 2014 [citado em 2018 maio 04];48(1):111-30. doi: http://dx.doi.org/10.1590/S0034$\underline{76122014000100005}$

19. Ferreira MS, Castiel LD. Which empowerment, which Health Promotion? Conceptual convergences and divergences in preventive health practices. Cad. Saúde Pública [Internet]. 2009 [citado em 2016 mar. 09];25(1):68-76. doi: http://dx.doi.org/10.1590/S0102-311X2009000100007

20. Wallerstein N. Powerlessness, empowerment, and health: implications for health promotion programs. Am J Health Promot [Internet]. 1992;6(3):197-205. doi: http://dx.doi.org/10.1590/1807-57622014.1217

21. Castells M. Redes de indignação e esperança: movimentos sociais na era da internet. Rio de Janeiro: Jorge Zahar; 2013.

22. Recuero R. Redes sociais na internet. Porto Alegre: Sulina; 2009.

23. Machado J. A mudança começa na Rede. Pesquisa sobre o uso das tecnologias da informação e da comunicação no Brasil: TIC Domićlíos 2013. São Paulo; 2014.

24. Maffesoli M. O tempo das tribos: o declínio do individualismo nas sociedades de massa. 2 ed. Rio de Janeiro: Forense Universitária; 1998.

25. ComScore. 2015 Brazil Digital Future in Focus [Internet]. 2015 maio 15 [citado em 26 out 2016]. Disponível em: https://www.comscore.com/por/Insights/Apresentacoes-e-documentos/2015/2015Brazil-Digital-Future-in-Focus

26. Hudnut-Beumler J, Po'e E, Barkin S. The use of social media for health promotion in hispanic populations: a scoping systematic review. JMIR Public Health and Surveillance [Internet]. 2016 [citado em 2018 maio 07];2(2):32. doi: https://doi.org/10.2196/publichealth.5579

27. Woolford SJ, Esperanza Menchaca ADM, Sami A, Blake N. Let's face it: patient and parent perspectives on incorporating a facebook group into a multidisciplinary weight management program. Child Obes [Internet]. 2013 [citado em 2018 maio 07];9(4):305-10. doi: https://doi.org/10.1089/chi.2013.0047

28. Veneroni L, Ferrari A, Massimino M, Clerici CA. Facebook in oncologia: revisione della letteratura. Recent Prog. Med [Internet]. 2015 [citado em 26 out. 2016];106(1):46-51. Disponível em: https://goo.gl/t5avFx

29. Santos NB. Comunicação, Educação e Promoção da Saúde na Internet. Brasília: Ministério da Saúde; 2006. (Coletânea de comunicação e informação em saúde para o exercício do controle social).

30. Cadaxa AG, Sousa MF, Mendonça AVM. Conteúdos promotores de saúde em campanhas de Aids no Facebook dos ministérios da saúde do Brasil e do Peru. Rev Panam Salud Publica [Internet]. 2015 [citado em 2018 maio 07];38(6):457-63. Disponível em: https://www.scielosp.org/pdf/rpsp/v38n6/ v38n6a04.pdf

31. Dziekaniak GV. Método para inclusão de conhecimento presente em mídias sociais no aprimoramento de plataformas de governo eletrônico. [tese]. Florianópolis: Universidade Federal de Santa Catarina; 2012.

32. Welch V, Petkovic J, Pardo JP, Rader T, Tugwell P. Interactive social media interventions to promote health equity an overview of reviews. Health Promot Chronic Dis Prev Can [Internet]. 2016 [citado em 26 out. 2016];36(4);63-75. Disponível em: https://www.ncbi.nlm.nih.gov/pmc/articles/PMC4964231/

33. Gabarron E, Wynn R. Use of social media for sexual health promotion: a scoping review. Glob Health Action [Internet]. 2016 [citado em 26 out. 2016];9. doi: https://dx.doi.org/10.3402\%2Fgha.v9.32193 
34. Martorell LB, Nascimento WF, Garrafa V. Redes sociais, privacidade, confiabilidade e ética: a exposição de imagens de pacientes no facebook. Interface (Botucatu) [Internet]. 2016 [citado em 2018 maio 07];20(56):13-23. doi: http://dx.doi.org/10.1590/1807-57622014.0902

35. Kite J, Foley BC, Grunseit AC, Freeman B. Please Like Me: facebook and public health communication. PLoS ONE [Internet]. 2016 [citado em 2018 maio 07];11(9). doi: https://doi.org/10.1371/journal. pone. 0162765

36. Cordeiro A. Martins CSF, Santos NB, Ribeiro RV, Petra T. Governo eletrônico e redes sociais: informação, participação e interação. RECIIS - Rev. Eletronica Comun. Inf. Inov. Saude [Internet]. 2012 [citado em: 23 out. 2016];6(2):1-8. Disponível em: http://www.reciis.icict.fiocruz.br/index.php/reciis/article/ view $/ 588$

37. Teixeira RR, Ferigato S, Lopes DM, Matielo DC, Sardenberg ML, Silva P, et al. Apoio em rede: a HumanizaSUS conectando possibilidades no ciberespaço. Interface (Botucatu) [Internet]. 2016 [citado em 2018 maio 07];20(57):337-48. doi: http://dx.doi.org/10.1590/1807-57622014.1217

38. Martino LMS. Teoria das mídias digitais: linguagens, ambientes, redes. Petrópolis: Vozes; 2015. 